\title{
Women’s Education and Fertility in Sub-Saharan Africa: Channels and Influence of Education on Fertility
}

\section{Theophile Ndjanmou Bieda*}

Department of Economics, Ecole des Sciences Economique et de Gestion, Universite du Quebec a Montreal, Canada

${ }^{*}$ Corresponding author: Ndjanmou TB, Department of Economics, Ecole des sciences Economique et de Gestion, Universite du Quebec a Montreal, Canada, Tel: 5142356499; E-mail: ndjanmou@yahoo.fr

Received date: March 02, 2017, Accepted date: March 13, 2017, Published date: March 18, 2017

Copyright: () 2017 Ndjanmou TB. This is an open-access article distributed under the terms of the Creative Commons Attribution License, which permits unrestricted use, distribution, and reproduction in any medium, provided the original author and source are credited.

\begin{abstract}
This paper seeks to contribute to the debate on the channels of influence of education on fertility in Sub-Saharan Africa (SSA). It uses individual level data of DHS of 14 countries of SSA to discuss the relative importance of the main channels that appear in the literature. The paper argues that compared to opportunity costs of children and the bargaining power of women, exposure to media and contraceptive use are the most influential channels through which education could cause fertility to decline consistently in SSA. These findings that were found robust with different measures of education and fertility suggest then, a better design of schooling policies as well as curricula in SSA, so as to minimize drop-out, reduce gender gap and prepare young girls regarding fertility concerns. In addition, contraceptive use should be promoted through media. The paper ends with a discussion on the causality issue and suggests a better setting in order to comfort its findings.
\end{abstract}

Keywords: Fertility; Education; Contraceptive

\section{Introduction}

Despite the worldwide declining trend of population observed since 1980 [1], the dynamic in Sub-Saharan Africa is still characterized by a high fertility rate of 5.1 children/woman along with a decreasing mortality rate. Bongaarts [2] even foreshadowed that the future pace of the decline in fertility in Sub-Saharan Africa will be slower than the pace of developed countries at the same comparable time of evolution, suggesting that some special measures need to be taken. With that respect, education and particularly that of women, has proved successful and efficient is declining population trend [3-5]. Moreover, the International Institute for Applied Systems Analysis [6] argued that education of women is one of the best ways of dealing with population, because while inducing fertility decline it also make it possible to benefit from demographic dividend 1 through human capital formation. In Sub-Saharan Africa (SSA), even though the evidence of the effect of women's education on fertility decline is also wellestablished [7], the question of the effectiveness of the transmission of its effects remains a concern. Indeed, the significant improvement in education observed in that region of the world over the last decades $[8,9]$, is only accompanied by a slight decrease in fertility. This highlights that there is still room for discussion on the mechanism through which education affects fertility in Sub-Saharan Africa. As proved by Cochrane [10], the relationship between education and fertility is not direct but transits through many variables and the abundant literature studying that relationship have usually attempted to measure the indirect effect of education on fertility. As a result, many actions using women's education as policy-variable to cause fertility to decline, have been found inefficient [2]. With the huge number of studies that have provided empirical evidence to support the influential role of many factors on fertility ${ }^{2}$, it appears interesting to investigate which of these well-established determinants of fertility could be an important channel of the influence of education. Inasmuch if well understood, the dynamic between education and fertility could foster the effects of education on fertility and thus help designing adequate policies so as to improve the educational investments in SubSahara Africa and better derive its benefits on fertility. The objective of this study is therefore to look at the key channels through which education could cause consistently a decline in fertility in Sub-Saharan Africa, with a value added on a discussion on the relative importance of these channels. To that end, two core questions will precisely help to study this issue: What are the main channels through which women's education influences fertility? And what is the sensitivity of the influence of those channels with respect to a change in fertility's measures and/or a change in education's measures? The first question will be an attempt of looking at the channels that are relevant and strong enough to be considered as a potential focus for fertility

1 The demographic transition has been used to explain the evolution of the population in Europe prior to the industrial revolution. This phenomenon was described by Thompson in 1926 and widely spread after the works of Davis and Notestein in 1945. De Bruijn (2006) presents the gist of this theory as a three stages phenomenon. The first stage is typically characterized by high fertility and high mortality, the second stage occurs when mortality drops but fertility remains high, owing inter alia to unintended fertility and resulting to an increase in population size. The third stage, known as fertility transition, appears when fertility drops inducing a steady state of the population at a lower level

2 Some authors have laid attention on media use and contraception (Ainsworth et al., 1996; Cheng, 2011; Darroch and Singh, 2013; Westoff and Bankole, 2001), others emphasized on mothers and infants health (Arnold et al., 1998; Ben-Porath, 1976; Breierova and Duflo, 2004; McCrary and Royer, 2006), some others on opportunity cost of having numerous children, (Becker, 1960; Easterlin, 1975; Ribar, 1992) for others the focus should be women's empowerment (Suguna, 2011; Upadhyaya et al., 2014; Upadhyaya and Karasek, 2012) 
policies, or to improve educational policies so as to ensure a real impact on fertility. The second question will enable to comfort the first one by varying the measures of the variables of interest. The rest of the document is organized into two main sections. The first one is dedicated to a theoretical framework based on the existing literature on fertility and education in Sub-Saharan Africa. The second section of the study is allotted to an empirical analysis where the derived results are discussed. The document ends with a conclusive part including some policy implications and some caveats.

\section{Theoretical Framework}

\section{Conceptualizing fertility}

The common theories describing fertility patterns are from fields as various as anthropology, sociology, political science, psychology, demography and economics. In economics, the approaches used are initially derived from the theory of consumer behavior to conceptualize the demand and the supply of children and then the actual fertility [11]. Furthering the work of Becker [11] and Easterlin [12] theorized fertility with a model that encompasses the contribution of many other disciplines. He ended up with a framework where the actual fertility is the result of the demand for children, the potential supply of children and the costs of fertility regulation. This theory is an equivalence of the consumers choice under constraint which in the case of fertility is the opportunity cost of children and time allocated to children rearing. In a similar setting, Butalo et al. [13], proposed a framework with various factors that should be considered while discussing the determinants of fertility. The Bulataos model also encompasses the three main building blocks from which the actual fertility is derived: the demand, the supply and the regulation of fertility. In addition, this latter model includes many others variables that gravitate around these building blocks and influence them. The demand for children or the intended fertility can be referred to as the number of children that a woman desired to have at the end of her childbearing life. According to the Butalo et al. [13] framework, this side of fertility is mainly driven by tastes, some constraints and the perception of children. However, for a couple the desired fertility is also the result of the joint decision of wife and husband. The supply of children is basically given by the natural fertility which is the potential number of children that a woman can have during her childbearing life. The supply of children in Bulataos model [13] is also determined by the same variables proposed earlier by Bongaarts [14]. Indeed, Bongaarts suggested that only biological and behavioural factors can have a direct effect on fertility, he then proposed three main intermediates variables: the exposure factors, especially the marriage; the deliberate marital control (contraception and induced abortion) and the natural marital fertility factors (breastfeeding, frequencies of sexual intercourses, sterility, intrauterine mortality, duration of fertility period). Bongaarts concluded that the total fertility is a combination of all these components for married individuals. Regarding regulation, when the supply side is lower than the demand side there is no need for regulation. But the regulation becomes crucial in the case of an inflated supply side that exceeds the demand side. The regulation acts, therefore, to cause the supply to meet the demand. It is worthwhile to notice that in some cases, some cultural behavior like abstinence during the childbearing or the breastfeeding may also act like regulation. However, the regulation considered in economics models is more often the conscious one which is the result of a decisional process of reducing fertility. To be effective, two elements need to be considered regarding the regulation of fertility: the motivation and the cost related to birth control. These costs include psychological and income cost as proposed by Becker [11].

\section{Education and fertility: the channels of the relationship}

This section discusses how the main determinants of fertility that appear in the literature could be the potential conveyor belts of the effects of education on fertility. The focus will be on the factors that are more likely to be shaped by education. Indeed, education is likely to affect the supply of children through the probability of marriage, age at marriage, age at first child birth as well as health [15-17]. The demand for children is likely to be affected by education through the perception of family size, the costs/benefits of children, the wifes market wage and occupation, culture and religion [18-23]. The regulation acts better on fertility when education enables women to have access and knowledge on contraception as well as information on opportunity costs of having children. In addition, education, through the regulation process influences also the demand for children by inducing a change in attitude and via communication between wife and husband.

\section{The opportunity cost of numerous children}

With the development of the modern world and the globalization, there is more and more a change in behaviour worldwide and particularly regarding the value of children. Becker [11] considered that having many children is costly in terms of opportunities so that there is a trade-off between the quality and quantity that leads people to choose fewer children that they can raise and educate well. Investigating the determinants of demand for children in Ethiopia, Tadesse and Sisay [24] found that education alters the economic value of children, resulting in a drop in children demand. Moreover, while studying the influence of childcare on the labor supply of married women, Ribar [25] found that childcare strongly affects negatively the labor opportunity of women. Since the labor supply is positively correlated to education, these findings suggest that education influences opportunity costs of children. In addition, educated women have more opportunities on the job market and in-come earning and find it, therefore, more costly to have many children. For Testa [26], the desired number of children for highly educated people are higher than the desired of children of lower educated one, but ultimately educated people do not achieve their intention for many constraints related basically to the time devoted to school. The opportunity cost of having numerous children can also be assessed through the effect of income on fertility. Education is positively correlated with income, but the direction of the effect of education on fertility through the channel of income is not well established. Indeed, on the one hand Muhoza et al. [19] found that the main factor that sustains higher fertility is poverty. According to him when income increases fertility should decrease. In another context, from the household theories of fertility, Baudin [27] argued that an increase in the income of men leads to an increase in fertility whereas an increase in the income of women induces a decrease in the demand for children. However, from the economic theories of fertility, it is established that when income increases there is a substitution from the quantity to the quality of children. An increase in income will result in an increase in demand for children. Nevertheless, some will increase the quantity demanded whereas others will increase the quality demanded so that the overall effect on the number of children is not clear a priori [11]. 


\section{Women's empowerment}

The role and place that women still have in Africa make it difficult to them to act on their fertility and mainly when they are married. Indeed, in SSA typically, women are devoted to childbearing, childcare and all related household duties. Usually, they are not involved in decision making and they have almost no control over household orientations. In a study on four countries from SSA (Guinea, Mali, Namibia and Zambia) with data of DHS, Upadhyaya and Deborah [28] found a slight but negative correlation between a high ideal number of children and women empowerment measured by the attitudes toward wife beating and refusing sex with husband. Reviewing 60 studies among which one-fifth conducted in Sub-Saharan Africa, Upadhyaya [29] found in almost all the studies, a positive association between women's empowerment and lower fertility, longer birth intervals and lower rates of unintended pregnancy. In addition, a previous study of Suguna [30] has pointed out that education empowers women and change their traditional role and status within the family. This confirms also the findings of Basu and Robert [17] stating that education influences fertility via gender equality and women's ability as it permits to women to benefit from the various schooling virtues as discipline, self-restraint, patience, routine and obedience of authority that enhance them as family-planners.

\section{Contraceptive use}

In many developing countries, the stall in fertility decline has been attributed to the lack of family planning services UN [1]. Education is typically the way through which couples and women, in particular, could acquire knowledge and abilities that could help them implementing family planning so as to adjust their desired number of children to a level that is convenient to their resources and expectations. This change in the desired number of children will then reflect on the final fertility. For Ezeh et al. [7] the stall in fertility decline in Eastern African was merely due among others to an increase in the unmet need for family planning. Mberu and Reed [31] explained the differentials fertility in Nigeria by a refusal of family planning by some tribes due to their religion. Bongaarts and John [32] for their own, attributed the difference in the pattern of fertility transition of Africa compared to that of developed countries at a same stage of transition, to low availability of family planning services. In their study, they also proved that the demand for family planning is one of the best predictors of fertility decline. Contraception is obviously quite related to family planning. A couple committed to manage their fertility will need contraception means to achieve their goal. Studying paths to lower fertility, Caldwell [33] concluded that better contraception use has had a significant role on fertility decline after 1960 in developed and developing countries. Moreover, in a study conducted in 2001, with data from 200 surveys in sub-Saharan Africa and 251 surveys from other countries, contraception use is proved to be associated with a low fertility as it enables a good management of the spacing and the desired number of children [34]. However, the study shows that for a comparable level of contraception use, the decline in trend is more visible for others regions than in SSA giving thus evidence of the necessity of improving contraceptive use inter alia through education. As other evidence of the effect of contraception on fertility, Bongaarts and John [32] found that the stall in fertility decline in SSA is the result of a low level of contraceptive use due to the lack of knowledge, limited sources of supply, the low quality and the cost of contraceptives. Moreover, they also pointed out some side effects and objections from husbands or other family members. In addition, some concerns such as moral and social acceptability are other factors explaining the stalling of fertility in Africa. Similarly, Ndahindwa [35] found in Rwanda that the high fertility was associated with unmet need for contraception, meaning that efforts intending to improve the use of contraception could help in reducing fertility. In that way, education is a mean of improving access, use and knowledge of contraception as proved by Douglas [36] who found that educational programs on sexuality affected positively the delaying of initiation of sex and increasing condom and contraceptive use among important youths.

\section{Exposure to Media}

Exposure to media appears to be a priori a relevant variable to explain the desired number of children. Indeed, modern view of the ideal family size and the opportunity cost of having few children are many factors advertised through media so as to shape the behaviour of individuals and change their taste and hence induce a decrease in fertility. Moreover, knowledge of contraception, family programs and population policies are commonly diffuse through media. Cheng [37] found that mass media and social networks play a key role in reducing fertility. More a woman is educated, more likely she is to understand and be open-minded to information from media.

\section{Measuring education and fertility}

While studying the relationship education and fertility, measures have always been a challenge leading in some cases to contrasted results regarding the signs and/or the magnitudes of the expected effects [10]. For example, in an evaluation of school entrance public policy, McCrary and Heather [38] measured education by enrollment and found just a small and statistically insignificant effect of education on fertility. Conversely found a much higher correlation between education and fertility while using the highest degree achieved to measure education. This observation draws attention to the importance of measures while studying the relationship educationfertility. Moreover, it raises the issue of comparability of studies, inasmuch to be comparable different studies need to use variables that have at least some overlap in the concepts that they measure. In many studies devoted to the relationship between education and fertility, education is measured by the years of schooling that is the total number of years of schooling that an individual has completed at a given date. Some others studies used enrollment or attainment, measuring the fact of being present at school for a given period. Even though these measures give an idea of the exposure of individuals to education, they are useless in capturing the extent to which individuals have learned from education. Given the poor quality of learning outcomes in SSA for low level of education, it could be sometimes hopeless to expect some difference in terms of learning outcome between those who are enrolled and those who are not Muvawala [39]. Hence, since the change in behaviour that is likely to affect fertility may occur only if there is are some learning outcome from education it is important to take into account not only enrollment but also some measures that could reflect the learning outcomes. On the fertility side, many studies used the Total Fertility Rate (TFR), the number of children per woman and the ideal number of children. Another relevant measure of fertility is age- specific fertility as suggested by Cochrane [10]. Moreover, some evidences proved that changes in fertility are different according to age-specific. Fertility is also measured in some cases by age at first marriage, age at first childbearing. Others measures of fertility include childbirth intervals, 
completed fertility rate (Children Even Born for women over age 49) and achievement rate of fertility (actual number divided by the desired number of children).

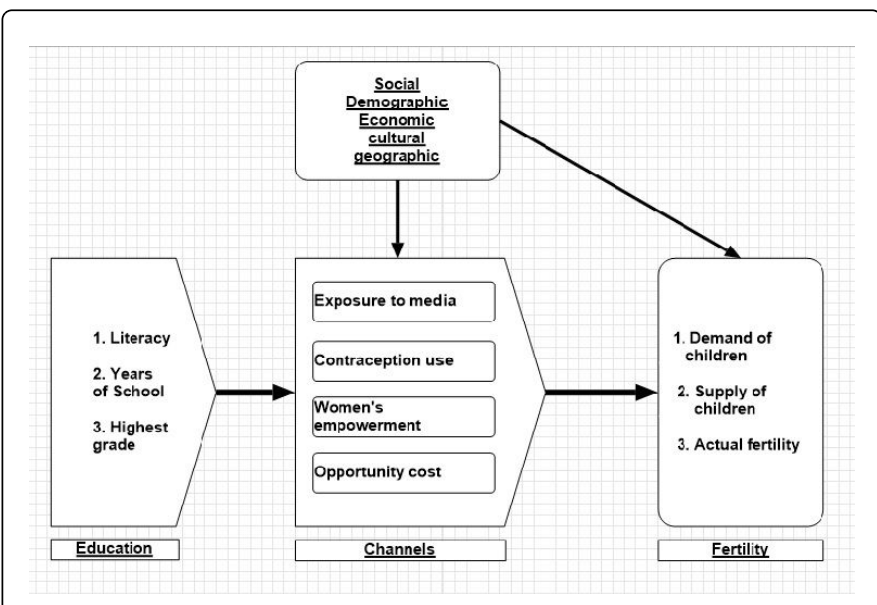

Figure 1: Diagram of the channels of the effects of education on fertility.

However, these indicators are sometimes difficult to measure because they require information for cohorts. Finally, the choice of fertility measures depends on the level of observation and the objective of the study. The Total Fertility Rate and the Age Specific Total Fertility Rate are relevant for a cross-country comparison whereas the number of children born, the age at first birth and the ideal number of children are mostly used at individual level studies.

From the above discussion based on the various studies that have been reviewed, the model that will be used in the empirical analysis is derived from the model of Bulatao. In this model, education is isolated and the other potential factors are considered like variables to control for. The model will enable to discuss empirically the relative importance of the channels of influence of education on fertility and the extent to which the measures matter as shown in Figure 1.

The underlying assumptions of this model are the followings:

- No recursive effects so that there is no endogeneity

- Education is completely exogenous

- The fertility variables are considered separately

- All the others potential determinants of channels or fertility are exogenous'.

Hence, with such assumptions the models will basically allow to capture only the correlations between the variables rather than the causal effects. The expected signs derived from the conceptual framework that have been discussed in section 2 are summarized in the Table 1 here below.

\begin{tabular}{|c|c|c|c|c|c|c|}
\hline \multicolumn{3}{|c|}{ Education } & \multirow[t]{2}{*}{ Channels } & \multicolumn{3}{|l|}{ Fertility } \\
\hline Literacy & $\begin{array}{l}\text { Years } \\
\text { of school }\end{array}$ & $\begin{array}{l}\text { Highest } \\
\text { grade }\end{array}$ & & $\begin{array}{l}\text { Number of } \\
\text { Children even } \\
\text { born }\end{array}$ & $\begin{array}{l}\text { Ideal number } \\
\text { of kids }\end{array}$ & $\begin{array}{l}\text { Age at } \\
\text { first marriage }\end{array}$ \\
\hline+ & + & + & Opportunity costs & $-/+$ & - & + \\
\hline+ & + & + & Media & - & - & + \\
\hline+ & + & + & empowerment & - & - & + \\
\hline+ & + & + & contraceptive use & - & - & $?$ \\
\hline
\end{tabular}

Table 1: Hypothetical expected signs of relation.

\section{Empirical Analysis}

\section{Empirical approach}

To discuss the relative influence of the channels the strategy will consist in looking at the influence of education on the channels and then the influence of the channels on fertility. For each step, the magnitudes of influence will be derived and discussed in Figure 2.

In the first step, the influence of education on the channels will be considered. For each channel, a regression will be performed, with some additional discussion on the measures of education. The model is the following:

\section{Channel $_{\mathrm{i}}=\alpha+\gamma$ Education $_{\mathrm{i}+} \beta X_{\mathrm{i}+} \varepsilon_{\mathrm{i}}$}

- Channel is the dependent variable one of the four channels considered in our models: empowerment, exposure to media, opportunity cost and Contraception use.

- a Stands for the intercept and coefficients
- $\quad \beta$ Stands for the effects of education on the channel

- $\quad \gamma$ Stands for the coefficients of controlled variable

- Education represents one of the three measure of education, total years of schooling, the highest grade or the literacy status.

- $\mathrm{X}$ is a set of variables to control for. These are: the age of the woman, the size of the household, the religion, the place of residence, the country, the marital status, wealth and the number of other wives.

- $\mathrm{E}$ is the error term and $\mathrm{i}$ is the subscript for a given individual $\mathrm{i}$. Since the dependent variable is either binomial or multinomial, a logistic regression or a multinomial regression will be performed for each measure of education and the level of association will be derived.

In the second step, the influence of the channels on fertility will be considered. The setting is the following:

Fertility $\quad i=\alpha+\gamma_{1} \mathrm{M} \quad$ ediai $+\gamma_{2}$ Empoweri $+\gamma_{3}$ Opportunityi $+\gamma_{4}$ Regulation $+\beta$ Educationi $+\theta X_{\mathrm{i}}+\varepsilon_{\mathrm{i}}$ 
Fertility is the dependent variable and represents one of the three measures of fertility accounting for the supply side (age at first marriage), the demand side (ideal number of children) or the actual fertility (number of children even born).

a: Stands for the intercept

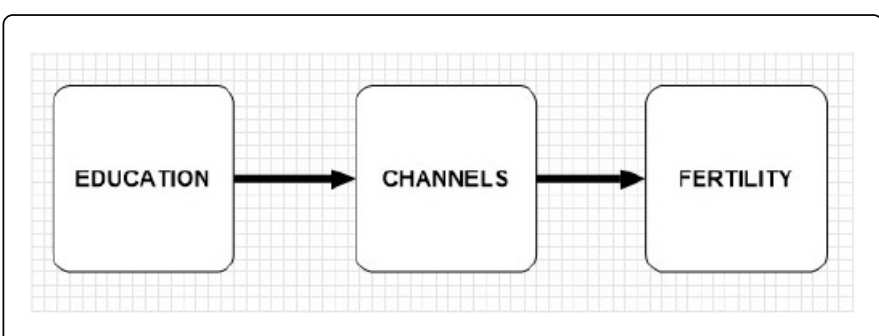

Figure 2: Dynamic of the empirical approach.

Media, Empowerment, Opportunity, and Regulation: are the four channels considered in the models.

Education: represents one measure of education: Total years of schooling, the highest grade or the literacy status.

$X$ : represents a set of variables to control for. These are: the age of the woman, the size of the household, the religion, the place of residence, the country, the marital status, wealth and the number of other wives.

\section{$E$ : is the error term and $\mathrm{i}$ is the subscript for a given individual $i$.}

For each measure of fertility, an OLS will be performed keeping the same setting in terms of variables to control for. The magnitude of the influence of the channels will be compared for each OLS. Given that there are some women who didn't yet enter into the childbearing life ${ }^{3}$ (basically those with zero as number of children even born), a Tobit regression will be run also for that measure of fertility.

\section{Data}

The data used are a set of 14 samples ${ }^{4}$, one per countries from SubSaharan Africa obtained from Integrated Demographic Survey (IDHS) 5 . For each country, the considered sample is the most recent survey from DHS. The variables of interest in the data set are those presented in the section 3.1. To measure education three variables are used: literacy, years of schooling and highest grade achieved. The literacy is a multinomial variable with three modalities: illiterate, Able to read only part of a sentence and Able to read a whole sentence. The years of schooling is a continuous variable measuring the total time in years spent at school. The highest grade achieved is a multinomial variable with four modalities: uneducated, primary, secondary and higher representing the highest school level achieved by the woman. On the fertility side, three variables are used to account for the demand for children, the supply of children and the final fertility.
These variables are respectively the ideal number of children, the age at first marriage and the number of children even born. It is worthwhile to notice that the measure used for the supply side (age at first marriage) induces a bias as it excludes non-married women. The four channels are the following, opportunity cost of children, exposure to media, women empowerment and regulation. The Opportunity cost of children is measured by the current working status of the woman like Kurnaz [40]. It is a dummy variable which is equal to 1 if the woman is currently working and 0 if not. However, a one-shot measure of the working status of the woman is not quite suitable to measure the extent to which job opportunities could affect fertility. But this is the best proxy for opportunity cost of children available in the data set. The Exposure to media is measured by a dummy variable equal to 1 if the woman has a television or reads newspapers and 0 if not.

The women's empowerment which is also a dummy variable equal to 1 if the woman is involved in decisions regarding family planning issues or if she can refuse to have sex with her husband and 0 otherwise. Notice that this variable is somehow tricky to conceptualize. The reality that is captured here is closer to the bargaining power of woman than the empowerment. The regulation is a multinomial variable measured by the use of contraception with three categories: Not using contraception, using traditional methods and using modern methods.

The pooled sample is composed of 162,172 women aged 15-49 years, with a higher representation of younger women as the mean age is 26.9 years. In majority, the sampled women are from the rural area (65\%). They are typically married or in couple $(75 \%)$ and live in monogamy arrangements ( $73 \%$ of married ones). They are basically Christian or Muslim and live in households of an average size of 6.5 individuals as shown in Table 2.

In the sample, only $44 \%$ of women can read properly a whole sentence. The others are either illiterate or can hardly read a whole sentence. Regarding education life time, the average time spent at school is 4.9 years. For the highest grade achieved, $70 \%$ of the women have achieved at most the primary level and hardly $5 \%$ have reached high school. On the fertility side, the average age at first marriage is estimated at 17.9 years. The ideal number of children averages at 4.9 and the mean number of children even born is 2.8 . The large values of the standard deviation of these measures (respectively 2.2 and 2.4) inform on the heterogeneity of these variables across the women.

The sample is composed of $56 \%$ of women who was working at the date of the survey. Globally, half of them are observed to be exposed to media as measured by the fact of possessing a television or reading newspapers. Regarding the process of decision-making for using family planning or the possibility to refuse having sex with husband, a large fraction of women is found empowered (78.4\%). For regulation, less than $25 \%$ of women are using contraception as a measure of fertility regulation. The modern and traditional methods are the ones commonly used by women implementing family planning.

3 All the infecund women have been excluded from the data set such that women with 0 as number of children are basically those that have not yet started their fertility life.

4 Countries: Benin 2011, Ethiopia 2011, Burkina Faso, Ghana 2008, Guinea 2012, Cote d'Ivoire 2011, Kenya 2008, Malawi 2010, Mali 2012, Mozambique 2011, Nigeria 2013, Zimbabwe 2010-11, Uganda 2011, Burkina Faso 2010.

5 IDHS: Integrated Demographic and Health Series, version 2.0, Minnesota Population Center and ICF International. 
Citation: Ndjanmou TB (2017) Women's Education and Fertility in Sub-Saharan Africa: Channels and Influence of Education on Fertility. J Glob

\begin{tabular}{|c|c|c|c|c|c|c|}
\hline & Variable & Mean & Median & Min & Max & Sd \\
\hline \multirow{5}{*}{$\begin{array}{l}\text { Social, Demographic and Economic } \\
\text { characteristics }\end{array}$} & Age & 26.9 & 26 & 15 & 49 & 8.34 \\
\hline & Live in urban Area & $34.70 \%$ & & & & \\
\hline & Live in Rural Area & $65.30 \%$ & & & & 0.48 \\
\hline & Muslim & $34.70 \%$ & & & & 0.48 \\
\hline & Christian & $60.10 \%$ & & & & 0.49 \\
\hline \multirow[b]{13}{*}{ Fertility Pattern } & Traditionalist & $2.80 \%$ & & & & 0.16 \\
\hline & Others & $2.50 \%$ & & & & 0.15 \\
\hline & Never been married & $25.30 \%$ & & & & 0.43 \\
\hline & Formerly in couple & $6.40 \%$ & & & & 0.24 \\
\hline & Currently in couple in the same house & $59.80 \%$ & & & & 0.49 \\
\hline & $\begin{array}{l}\text { Currently in couple not in the same } \\
\text { house }\end{array}$ & $8.50 \%$ & & & & 0.28 \\
\hline & Households size & 6.4 & 6 & 1 & 49 & 3.5 \\
\hline & Number of children even born & 2.8 & 2 & 0 & 18 & 2.67 \\
\hline & Ideal number of kids & 4.9 & 4 & 0 & 18 & 2.37 \\
\hline & Age at first marriage & 17.9 & 17 & 4 & 48 & 4.05 \\
\hline & Total years of schooling & 4.9 & 5 & 0 & 23 & 4.75 \\
\hline & Uneducated & $37.00 \%$ & & & & 0.48 \\
\hline & Primary school & $32.50 \%$ & & & & 0.47 \\
\hline \multirow[b]{7}{*}{ Education Pattern } & Secondary school & $26.10 \%$ & & & & 0.44 \\
\hline & High school & $4.50 \%$ & & & & 0.21 \\
\hline & Illiterate & $48.50 \%$ & & & & 0.5 \\
\hline & Able to real only part of sentence & $7.60 \%$ & & & & 0.26 \\
\hline & Able to read whole sentence & $43.90 \%$ & & & & 0.5 \\
\hline & Has television or read newspapers & $43.70 \%$ & & & & 0.5 \\
\hline & Currently working & $56.30 \%$ & & & & 0.5 \\
\hline \multirow[b]{4}{*}{ Channels } & $\begin{array}{l}\text { Women can have sex or decide for } \\
\text { family planning }\end{array}$ & $99.00 \%$ & & & & 0.1 \\
\hline & Not using contraception & $77.40 \%$ & & & & 0.42 \\
\hline & Tradition methods of contraception & $3.50 \%$ & & & & 0.18 \\
\hline & Modern methods of contraception & $19.10 \%$ & & & & 0.39 \\
\hline
\end{tabular}

Table 2: Descriptive statistics of the sample.

\section{Results and Discussion}

\section{Education and the channels}

Table 3, displays the results for the correlation between each of the channels and education. Logit and multi-logit regression have been performed and respectively Odd Ratios (OR) and Relative Risk Ratios
(RRR) are provided. Basically, it appears that the channels that are importantly influenced by education are exposure to media, Regulation and to some extent women empowerment. Indeed, education does not seem to increase the likelihood of the opportunity cost measured by the current working status of the woman as the Odd Ratios are near to 1 for all the measures of education. 
Page 7 of 15

For the variable Women's empowerment, one additional year of schooling affect slightly the probability to be empowered (1.04 times more). Using literacy, the probability (odd) of been empowered is 1.26 times more for women that can read a whole sentence than those that are illiterate. With the highest grade achieved, the influence of education is more visible for secondary and higher grades.

\begin{tabular}{|c|c|c|c|c|c|}
\hline \multicolumn{6}{|l|}{ Outcome variables } \\
\hline \multirow[t]{2}{*}{ Variables } & \multirow[t]{2}{*}{ Opportunity cost (OR) } & \multirow[t]{2}{*}{ Empowerment (OR) } & \multirow[t]{2}{*}{ Media (OR) } & \multicolumn{2}{|c|}{ Contraceptive use (reference=Not using), (RRR) } \\
\hline & & & & Traditional method & Modern method \\
\hline \multirow[t]{2}{*}{ Education life time } & $0.98^{\star \star *}$ & $1.04^{* \star *}$ & $1.27^{* \star *}$ & $1.100^{\star \star \star}$ & $1.071^{* * *}$ \\
\hline & -0.001 & -0.007 & -0.002 & -0.004 & -0.002 \\
\hline Literacy=Unable to read part of sentence & \multicolumn{5}{|l|}{ Reference } \\
\hline \multirow[t]{2}{*}{ Literacy=Able to read only part of sentence } & $0.96^{*}$ & 0.92 & $3.07^{* \star *}$ & $1.39^{* \star *}$ & $1.80^{* * *}$ \\
\hline & -0.02 & -0.08 & -0.07 & -0.08 & -0.047 \\
\hline \multirow[t]{2}{*}{ Literacy=Able to read whole sentence } & $0.69^{\star \star \star}$ & $1.26^{\star \star \star}$ & $8.19^{\star \star \star}$ & $1.82^{\star \star *}$ & $2.31^{\star \star \star}$ \\
\hline & -0.01 & -0.08 & -0.11 & -0.0703 & -0.042 \\
\hline Grade of education=Uneducated & \multicolumn{5}{|l|}{ Reference } \\
\hline \multirow[t]{2}{*}{ Grade of education=Primary } & $0.91^{* \star *}$ & 1.01 & $2089^{* \star *}$ & $1.844^{\star \star \star}$ & $2.36^{\star \star *}$ \\
\hline & -0.01 & -0.06 & -0.04 & -0.08 & -0.46 \\
\hline \multirow[t]{2}{*}{ Grade of education=Secondary } & $0.66^{* * *}$ & $1.4^{* * *}$ & $10.04^{* \star *}$ & $2.64^{* * *}$ & $2.53^{\star * *}$ \\
\hline & -0.01 & -0.12 & -0.17 & -0.128 & -0.057 \\
\hline \multirow[t]{2}{*}{ Grade of education=Higher } & 0.95 & $2.74^{\star \star *}$ & $48.25^{\star \star \star}$ & $3.38^{\star \star \star}$ & $2.444^{\star \star \star}$ \\
\hline & -0.03 & -0.54 & -3.1 & -0.216 & -0.082 \\
\hline Controlled variables & Yes & Yes & Yes & Yes & Yes \\
\hline
\end{tabular}

Table 3: Results of the regression of the channels on education.

Indeed, the level of empowerment is almost the same for uneducated women and for those of primary school, whereas women of secondary school have 1.4 times more chance to be found empowered than uneducated ones and those with higher grade have 2.7 times more change to be found empowered than uneducated women. For the exposure to media, the chance to be found exposed to media is 8 times more for women that can read properly a sentence than for illiterate ones. Women of secondary school have 10 times more chance to be exposed to media than uneducated ones and those with higher grade have nearly 50 times more chance to be exposed to media than uneducated women. The contraceptive use channel is also strongly associated to education. Compared to women who do not use contraception, the risk of using traditional means is 1.1 time more for each additional year of schooling. This relative risk increases as education grade increases and is 3.4 times more for women of higher grade relatively to uneducated women. The same trend holds for modern methods of contraception. However, Traditional method seems to respond better to education that modern methods for high level of education. This could be due to the relative low availability (in terms of cost and services) of modern methods compared to traditional methods. Globally, the effect of education on opportunity cost and woman empowerment is not perceptible for low level of education. Only exposure to media and contraceptive use depict visible effect even for low level of education.

\section{Fertility and the channels}

Total children ever born and education and channels: Table 4 shows the results from the OLS regression along with Tobit regression with the total number of children even born as the outcome variable. Three different settings are used to account each for one measure of education (years of schooling, literacy status and highest grade achieved).

The results show that each additional year of schooling is associated with 0.11 less children ( 0.12 with Tobit). This result is in line with others findings in similar contexts. For example Ainsworth [41] also found in Cte divoire a 0.11 decrease of the number of children per additional year of education with OLS regression and 0.15 decrease with Tobit regression. Osili and Bridget [42] even found a much higher magnitude of 0.26 less children per additional year of schooling in Nigeria. For the literacy, compared to illiterate women, those who are able to read only part of a sentence have 0.2 less children. Those who can read a whole sentence have also fewer children with a higher magnitude (-0.60). While using the highest grade achieved, compared to uneducated women, those with primary grade have 0.3 less children, 
Citation: Ndjanmou TB (2017) Women's Education and Fertility in Sub-Saharan Africa: Channels and Influence of Education on Fertility. J Glob

Page 8 of 15

those with secondary grade have 0.7 less children and those with the high school grade have up to 1.8 less children. These results are confirmed by the Tobit model with a systematic higher magnitude of effects (Table 3). These results are consistent with the findings of Abadian [43] who used country level data from the 1992 World Demographic Report on 54 countries and found a negative correlation of magnitude 0.039 between secondary education and total fertility rate. For the regulation, a woman who uses traditional means of contraception has fewer children that a woman who doesn't. The magnitudes of the effects are small in the models using the years of schooling (-0.07) and grade achieved (-0.05), but higher in the setting using literacy as a measure of education. The effects of modern contraceptive methods are not significant while using the years of education or grade achieved. But it is found significant with the expected sign in the setting using literacy as a measure of education. However, the Tobit regressions give significant results but with signs opposite to those expected. Regarding the opportunity cost of having numerous children as measured by the current working status, the working women seem to have less children that those who was not working. Indeed, the difference is significant and roughly 0.12 for all the measures of education.

\begin{tabular}{|c|c|c|c|c|c|c|}
\hline \multirow[t]{3}{*}{ Variables } & \multicolumn{6}{|c|}{ Outcome variable: Total number of children ever born } \\
\hline & \multicolumn{2}{|l|}{ Model 1} & \multicolumn{2}{|l|}{ Model 2} & \multicolumn{2}{|l|}{ Model 3} \\
\hline & (OLS 1) & (Tobit 1) & (OLS 2) & (Tobit 2) & (OLS 3) & (Tobit 3) \\
\hline \multirow[t]{2}{*}{ Education life time } & -0.109 & -0.124 & & & & \\
\hline & -0.00111 & -0.00144 & & & & \\
\hline \multirow{3}{*}{$\begin{array}{l}\text { Literacy=Unable to read part of sentence } \\
\text { Literacy=Able to read only part of sentence }\end{array}$} & \multicolumn{6}{|l|}{ Reference } \\
\hline & & & $-0.224^{\star * *}$ & $-0.242^{\star * *}$ & & \\
\hline & & & -0.0151 & -0.019 & & \\
\hline \multirow[t]{2}{*}{ Literacy=Able to read whole sentence } & & & $-0.598^{\star * *}$ & $-0.744^{* * *}$ & & \\
\hline & & & -0.0107 & -0.0136 & & \\
\hline Grade of education=uneducated & \multicolumn{6}{|l|}{ Reference } \\
\hline \multirow[t]{2}{*}{ Grade of education=Primary } & & & & & $-0.265^{\star \star *}$ & $-0.278^{\star * *}$ \\
\hline & & & & & -0.0106 & -0.0131 \\
\hline \multirow[t]{2}{*}{ Grade of education=Secondary } & & & & & $-0.757^{\star \star \star}$ & $-0.946^{\star \star *}$ \\
\hline & & & & & -0.0128 & -0.0167 \\
\hline \multirow[t]{2}{*}{ Grade of education=Higher } & & & & & $-1.856^{\star * *}$ & $-2.239^{* \star *}$ \\
\hline & & & & & -0.0209 & -0.0288 \\
\hline Regulation de la fertility=No regulation & \multicolumn{6}{|l|}{ Reference } \\
\hline \multirow[t]{2}{*}{ Regulation de la fertility=Traditional methods } & $-0.0572^{* * *}$ & 0.0208 & $-0.156^{\star \star *}$ & $-0.0752^{* * *}$ & $-0.098^{* * *}$ & -0.0169 \\
\hline & -0.0203 & -0.0249 & -0.0206 & -0.0253 & -0.0203 & -0.0249 \\
\hline \multirow[t]{2}{*}{ Regulation de la fertility=Modern methods } & $0.0306^{\star \star \star}$ & $0.176^{\star \star *}$ & $-0.0227^{\star *}$ & $0.137^{\star \star \star}$ & 0.0048 & $0.152^{* * *}$ \\
\hline & -0.01 & -0.0125 & -0.0102 & -0.0127 & -0.01 & -0.0125 \\
\hline \multirow[t]{2}{*}{ Woman is currently working $=1$} & $-0.110^{* \star *}$ & $0.0292^{\star * *}$ & $-0.119^{* * *}$ & 0.0155 & $-0.107^{\star \star *}$ & $0.0322^{* * *}$ \\
\hline & -0.00784 & -0.0101 & -0.00802 & -0.0103 & -0.00787 & -0.0101 \\
\hline \multirow[t]{2}{*}{ Has television or read newspapers $=1$} & $-0.0896^{* * *}$ & $-0.218^{* * *}$ & $-0.268^{\star * *}$ & $-0.348^{\star * *}$ & $-0.226^{* * *}$ & $-0.297^{\star \star *}$ \\
\hline & -0.00951 & -0.0125 & -0.00992 & -0.0128 & -0.00955 & -0.0123 \\
\hline \multirow[t]{2}{*}{ Woman can refuse sex or decide about family planning=1 } & $-0.184^{\star * *}$ & -0.0688 & $-0.250^{\star * *}$ & $-0.119^{\star \star *}$ & $-0.198^{\star * *}$ & $-0.0760^{*}$ \\
\hline & -0.0374 & -0.0435 & -0.0382 & -0.0443 & -0.0375 & -0.0435 \\
\hline \multirow[t]{2}{*}{ Constant } & $-3.293^{\star * *}$ & $-6.324^{* * *}$ & $-2.631^{* * *}$ & $-6.487^{\star \star *}$ & $-2.628^{\star * *}$ & $-6.398^{\star * *}$ \\
\hline & -0.0566 & -0.0684 & -0.0579 & -0.0698 & -0.0569 & -0.0685 \\
\hline
\end{tabular}




\begin{tabular}{|l|l|l|l|l|l|l|}
\hline \multirow{2}{*}{ Sigma } & & $1.662^{* * *}$ & & $1.691^{* * *}$ & & $1.663^{* * *}$ \\
\cline { 2 - 7 } & & -0.00349 & & -0.00356 & -0.00349 \\
\hline Controlled variable & Yes & Yes & Yes & Yes & Yes & Yes \\
\hline Number of observations & $1,59,243$ & $1,59,243$ & $1,58,050$ & $1,58,050$ & $1,59,283$ & $1,59,283$ \\
\hline R-squared & 0.712 & & 0.7 & & 0.72 \\
\hline Standard errors in parentheses ${ }^{* * *} p<0.01,{ }^{* *} p<0.05,{ }^{*} p<0.1$ & & & \\
\hline
\end{tabular}

Table 4: Regression of total number of children ever born and channels.

However, the Tobit regression displays different results as nonworking women seem to have less children that working ones but this is not consistent in the setting using literacy as a measure of education. However, given that the occupational status of the woman is a one-shot measure, this results are to be taken with caution. Indeed, one should expect a long working period to be influential on the number of children even born. In a more consistent and robust setting, Bloom [44] worked on a panel of 97 countries (SSA included) with a span of 5 years and concluded to a loss of 1.9 year of woman's labor supply during her fertile years for each child born. For exposure to media as measured by having a television or reading newspapers, women that are exposed to media have fewer children that those who are not. Indeed, the magnitude is nearly 0.10 less children while using total years of schooling, but higher with the highest grade achieved $(-0.23)$ and much higher with the literacy status of the woman $(-0.27)$. The magnitudes of the effects are comforted by the Tobit results and the sign as well. Empowered women have nearly 0.20 less children that those who are not, in the models using years of schooling and education grade achieved. With the variable literacy the effect is slightly higher (0.25). The Tobit models confirm the sign of the effects but have lower magnitudes. This result is in line with? who reviewed up to 60 studies on the relationship between the number of children and many measures of women empowerment. They concluded to a consistent negative relationship between some measures of women empowerment (refuse sex, household decision making, etc.) and the total fertility of women.

\section{The Ideal number of children, education and channels}

Table 5, shows the results from the OLS regression for the demand for children measured by the ideal number of children. Three models are presented, each for one measure of education.

From these results one can see that each additional year of schooling tends to reduce the desired number of children by 0.11 . Similar results were found in a study on the desired fertility and years of schooling in Ethiopia by Tadesse and Sisay [24]. Using a poison regression they found a negative, slight but significant marginal effect of magnitude 0.0531 of years of schooling on the desired number of children. Using literacy to measure education yields to 0.36 less children desired for women who can read part of a sentence and a desire of 0.73 less children for those who can read a whole sentence compared to illiterate women. With a paths analysis model on Africa data on a span of 12 years, Westoff [45] found comparable results. Indeed, he reported a positive correlation of magnitude 0.47 between uneducated women and the desired for more children and a slight but positive correlation (0.192) between educated women and women wanting no more children.

\begin{tabular}{|c|c|c|c|}
\hline \multirow[t]{2}{*}{ Variables } & \multicolumn{3}{|c|}{ Outcome variable: Ideal number of children } \\
\hline & (OLS 1) & (OLS 2) & (OLS 3) \\
\hline \multirow[t]{2}{*}{ Education life time } & $-0.112^{\star \star *}$ & & \\
\hline & -0.00151 & & \\
\hline Literacy=Unable to read part of sentence & \multicolumn{3}{|l|}{ Reference } \\
\hline \multirow[t]{2}{*}{ Literacy=Able to read only part of sentence } & & $-0.365^{\star * *}$ & \\
\hline & & -0.0202 & \\
\hline \multirow[t]{2}{*}{ Literacy=Able to read whole sentence } & & $-0.733^{* * *}$ & \\
\hline & & -0.0143 & \\
\hline Grade of education=Uneducated & \multicolumn{3}{|l|}{ Reference } \\
\hline \multirow[t]{2}{*}{ Grade of education=Primary } & & & $-0.572^{* * *}$ \\
\hline & & & -0.0145 \\
\hline Grade of education=Secondary & & & $-1.083^{* * *}$ \\
\hline
\end{tabular}




\begin{tabular}{|c|c|c|c|}
\hline & & & -0.0174 \\
\hline \multirow[t]{2}{*}{ Grade of education=Higher } & & & $-1.589^{* * *}$ \\
\hline & & & -0.0281 \\
\hline Regulation de la fertility=No contraception & \multicolumn{3}{|l|}{ Reference } \\
\hline \multirow[t]{2}{*}{ Regulation de la fertility=Traditional methods } & $-0.283^{\star * *}$ & $-0.366^{\star * *}$ & $-0.308^{\star \star \star}$ \\
\hline & -0.0273 & -0.0276 & -0.0274 \\
\hline \multirow[t]{2}{*}{ Regulation de la fertility=Modern methods } & $-0.349^{* * *}$ & $-0.389^{* * *}$ & $-0.358^{* * *}$ \\
\hline & -0.0135 & -0.0137 & -0.0135 \\
\hline \multirow[t]{2}{*}{ Woman is currently working $=1$} & $-0.0452^{* * *}$ & $-0.0542^{* * *}$ & $-0.0465^{* * *}$ \\
\hline & -0.0106 & -0.0108 & -0.0107 \\
\hline \multirow[t]{2}{*}{ Has television or read newspapers $=1$} & $-0.284^{\star * *}$ & $-0.383^{\star * *}$ & $-0.344^{* * *}$ \\
\hline & -0.0131 & -0.0133 & -0.013 \\
\hline \multirow[t]{2}{*}{ Woman can refuse sex or decide about family planning } & -0.00698 & -0.0678 & -0.0172 \\
\hline & -0.051 & -0.0515 & -0.0511 \\
\hline \multirow[t]{2}{*}{ Constant } & $4.111^{\star \star *}$ & $4.053^{\star \star *}$ & $4.181^{* \star *}$ \\
\hline & -0.0769 & -0.0777 & -0.0772 \\
\hline Controlled variables & Yes & Yes & Yes \\
\hline Number of observations & $1,51,993$ & $1,50,907$ & $1,52,032$ \\
\hline R-squared & 0.353 & 0.342 & 0.35 \\
\hline
\end{tabular}

Table 5: Regression of Ideal number of children, education and channels.

The results with grade achieved give also the expected signs. Compared to uneducated, women with primary level desire 0.57 less children, those with secondary level desire 1.08 less and those with high school grade desire 1.59 less children. A study on four countries from East Africa Muhoza et al. [19], showed that in Kenya higher educated people have a fertility preference close to the replacement rate whereas uneducated people have an uncontrolled fertility. Conversely, from the same study, no significant difference between educated and uneducated people was found in Rwanda regarding fertility preferences. For the regulation, this variable is conceptually unlikely to influence the desired number of children, but the reverse. However, in terms of correlations, women who use traditional means of contraception are associated with the desire of fewer children (respectively 0.28 with years of schooling, 0.37 with literacy and 0.31 with grade achieved) than women who are not using contraception. The results are the same for women using modern means of contraception with a higher magnitude (respectively 0.35 with years of schooling, 0.39 with literacy and 0.0 .36 with grade achieved). Westoff [45] found also at country level a 0.64 correlation between contraceptive prevalence and the desire for no more children. Women that were found working at the survey time as a measure of the opportunity cost of children, desire fewer children than those who were not working at all. However, the difference is hardly 0.05 less children. Tadesse and Sisay [24] in Ethiopia found a 0.3 decrease of the desired number of children due to job opportunity, but this result was not significant. For exposure to media, this variable has a high effect on lowering the desired number of children. Indeed, with all the three models, women exposed to media desire roughly 0.3 less children than women less exposed to media. The magnitude is nearly 0.4 in the setting using literacy to measure education. These results are similar to the findings of Westoff and Akinrinola [46] who used DHS data from a survey conducted in 1992-1993 in six countries in SSA to study the determinants of the desired number of children. They found from OLS estimation that exposure to television reduce from 1.9 to 2.8 the desired number of children of married women and from 0.7 to 1.6 the desired number of children of never married women. The results for newspapers are also similarly conclusive. Indeed, they reported a reduction from 1.1 to 2.1 number of desired children for married women and 0.4 to 1.7 for never married women. The desire of children is not significantly affected by the variable women's empowerment. The effect reaches hardly 0.01 with years of schooling, 0.02 with grade achieved and 0.07 with literacy. This result contrasts a little bit with who reviewed 60 studies on the relationship between the number of children and many measures of women empowerment. Indeed, the authors concluded to a consistent negative relationship between some measures of women empowerment (refuse sex, household decision making, etc.) with the desire of children but less strong than the correlation number of children as a measure of fertility. However, as discussed earlier, this contrast could be the result of the quality of the variable used to measure empowerment. 


\section{The age at first marriage and taking various measures of education}

Table 6 shows the results from the OLS regression for the supply of children as measured by the age at first marriage. Three models are equally presented, each for one measure used for education.

Each additional year of schooling results in a postponement of marriage for basically 0.29 years. Using literacy status measure to account for education, women who are able to read only part of sentence get married 0.40 year later than illiterate and those who can read a whole sentence get married 1.64 years later than illiterate. The results with the grade achieved are similar. Indeed, women with primary level get married 0.58 years later than uneducated one, those with secondary level get married 2.33 years later than uneducated women and those with high school grade married much more lately (5.22 years later). Equivalent results have been found by Westoff [45] who found that women that married by 20 years old are positively correlated with low education (0.37) and negatively correlated with relatively high education $(-0.34)$.

For the regulation, this variable is not likely to influence the age at first marriage, but the reverse. However, in terms of correlations women that got married earlier are likely to use contraception more than those who got married later. These results are somehow rational given that women that got married later tend to catch up with their fertility desired. Early marriage is associated with the unlikeness of using contraception as confirmed by Westoff [45] who found a correlation of -0.213 between women that married before 20 and contraception use. The correlation between the working status of the women and the age at first marriage do not have the expected sign and is found non-significant while using literacy status of the woman to measure education. Women exposed to media are found with a later age at first marriage than those less exposed to media. The magnitude is 0.11 in the setting using the years of education, 0.46 for literacy and 0.30 for grade achieved. These results are comforted by the findings of Westoff and Akinrinola [46] who used Demographic and Health Surveys from 1992-1993 and found significant effects of exposure to the mass media among women age 15-24, on age at first marriage. Indeed, the hazard ratio estimates ranged from 0.3 to 0.9 for television and from 0.3 to 0.5 for newspapers. Women empowerment is found associated with a postponement of age at first marriage of 0.36 year in the setting with years of schooling, 0.48 with literacy and 0.37 with highest grade.

\begin{tabular}{|c|c|c|c|}
\hline \multirow[t]{2}{*}{ Variables } & \multicolumn{3}{|c|}{ Outcome variable: Age at first marriage } \\
\hline & (OLS 1) & (OLS 2) & (OLS 3) \\
\hline Education life time & $0.294^{* \star *}-0.00331$ & & \\
\hline Literacy=Unable to read part of sentence & \multicolumn{3}{|l|}{ Reference } \\
\hline Literacy=Able to read only part of sentence & & $0.389^{* \star \star}-0.0431$ & \\
\hline Literacy=Able to read whole sentence & & $1.663^{\star * \star}-0.0312$ & \\
\hline Grade of education=Uneducated & \multicolumn{3}{|l|}{ Reference } \\
\hline Grade of education=Primary & & & $0.571^{\star \star \star}-0.0296$ \\
\hline Grade of education=Secondary & & & $2.345^{\star \star \star}-0.0384$ \\
\hline Grade of education=Higher & & & $5.286^{* * *}-0.067$ \\
\hline Regulation de la fertility=No contraception & \multicolumn{3}{|l|}{ Reference } \\
\hline Regulation de la fertility=Traditional methods & $-0.102^{*}-0.0561$ & $0.142^{* \star}-0.0573$ & $-0.0132-0.056$ \\
\hline Regulation de la fertility=Modern methods & $-0.499^{* * *}-0.0284$ & $-0.410^{* * *}-0.0291$ & $-0.446^{\star * *}-0.0284$ \\
\hline Woman is currently working=1 & $-0.0773^{* * *}-0.0231$ & $-0.0361-0.0237$ & $-0.0831^{* * *}-0.0231$ \\
\hline Has television or read newspapers $=1$ & $0.190^{\star \star \star}-0.0286$ & $0.538^{* \star *}-0.0294$ & $0.371^{* * *}-0.0282$ \\
\hline Woman empowerment=1 & $0.336^{* * *}-0.0944$ & $0.459^{* * *}-0.0965$ & $0.349^{* * *}-0.0944$ \\
\hline Constant & $14.00^{\star \star \star}-0.152$ & $14.15^{\star \star \star}-0.156$ & $14.17^{\star \star *}-0.152$ \\
\hline Controlled variables & Yes & Yes & Yes \\
\hline Number of observations & 118,246 & 117,327 & 118,271 \\
\hline R-squared & 0.211 & 0.18 & 0.212 \\
\hline
\end{tabular}

Table 6: Regression of the age at first marriage and the channels. 


\section{The relative importance of channels}

From the various regressions that have been discussed the following table summarizes the relative importance of channels in terms of the magnitude of correlation with a level of significance $P_{j} 0.1$, in a setting using one specific measure of fertility in rows and one measure of education in columns (Table 7).

\begin{tabular}{|l|l|l|l|}
\hline \multirow{4}{*}{ Children even born } & Years of schooling & Literacy & Grade \\
\hline \multirow{5}{*}{ Ideal number of children } & Empower & Media & Media \\
\cline { 2 - 4 } & Opportunity cost & Empower & Opportunity cost \\
\cline { 2 - 4 } & Media & regulation & regulation \\
\cline { 2 - 4 } & regulation & & \\
\hline Age at first marriage & regulation & regulation & regulation \\
\cline { 2 - 4 } & Media & Media & Media \\
\cline { 2 - 4 } & Opportunity cost & Opportunity cost & Opportunity cost \\
\hline & regulation & Media & regulation \\
\cline { 2 - 4 } & Empowerment & Empowerment & Media \\
\cline { 2 - 4 } & Media & regulation & Empowerment \\
\cline { 2 - 4 } & Opportunity cost & & Opportunity cost \\
\hline
\end{tabular}

Table 7: Summarizing of the relative importance of the channels.

Globally, regulation and exposure to media appear to be potentially the most import channels as they have the relatively stronger and consistent correlations in all the settings. This is particularly visible while using ideal number of kids or age at first marriage as measures of fertility. The variable number of children even born that measures the actual or final fertility is basically the result of the demand (ideal number of kids) and the supply (age at first marriage) under the constraint of regulation as discussed in Becker [11].

\section{The issue of measures}

The disparities observed in the results while using different measures of education and fertility and the accuracy of the results shows that measures matter. Indeed, the use of number of children even born gives a higher $\mathrm{R}(71 \%)$ than all the other measures of fertility, but this setting replicates the expected sign of correlation derived from the literature only with the use of literacy as a measure of education. Moreover, this setting fails to give evidence of the potential influence of regulation that is well establish in the literature and the consistency of the results is not strong enough (different conclusion with different measures of education) (Table 8).

The ideal number of kids accounts for the demand side of fertility and exhibits a much lower $\mathrm{R}(35 \%)$ than the previous measure but it has the merit of replicating perfectly the expected signs of correlation admitted in the existing literature. In addition, the conclusion while using this variable to measure fertility are consistent with all the measures of education (Empowerment is not significant for all the measures of education). The main drawback of this measure is that this variable could change from a period to another for the same women as illustrated by Kodzi et al. [47] who used data from multiple surveys to assess the stability of intended fertility in a cohort of rural Ghanaian women over a period of five years. They found that $20 \%$ of the surveyed women changed their fertility preference from one interview to another.

The age at first marriage account for the supply side of fertility and yields a much lower $\mathrm{R}(21 \%)$ than the other measures. It also replicates all the expected signs of the literature. However, this measure is somehow restrictive as it excludes the non-married women whose fertility is also part of the debate inducing, therefore, a bias in the analysis. The consistency of the results is not strong enough (different conclusion with different measures of education). Regarding specifically the measures of education, the years of schooling and the highest grade achieved should be preferred in this analysis as they yield the lower values of coefficient of variation for the estimates.

\begin{tabular}{|l|l|l|l|l|}
\hline \multirow{2}{*}{ Actual fertility: number of children even born } & Criteria of assessment & Years of schooling & Literacy & Grade \\
\hline & $\mathrm{R}$ & $71.20 \%$ & $70.00 \%$ & $72.00 \%$ \\
\cline { 2 - 6 } & Coeff. (p-val) & All significant & Not for Cost & All as expected \\
\cline { 2 - 5 } & Coefficient of variation & $1 \%$ & $4.30 \%$ & $2.30 \%$ \\
\cline { 2 - 5 } & Sign of the coefficient & Except regulation & All as expected & Except regulation \\
\hline
\end{tabular}


Page 13 of 15

\begin{tabular}{|l|l|l|l|l|}
\hline \multirow{3}{*}{ Demand for children: Ideal number of kids } & $\mathrm{R}$ & $35.30 \%$ & $34.20 \%$ & $35.00 \%$ \\
\cline { 2 - 5 } & Coeff. (p-val) & Except empowerment & Except empowerment & Except empowerment \\
\cline { 2 - 5 } & Coefficient of variation & $1.30 \%$ & $3.70 \%$ & $2.00 \%$ \\
\cline { 2 - 5 } & Sign of the coefficient & All as expected & All as expected & All as expected \\
\hline \multirow{3}{*}{ Supply for children: Age at first marriage } & $\mathrm{R}$ & $21.10 \%$ & $18.00 \%$ & $21.2 .0 \%$ \\
\cline { 2 - 5 } & Coeff. (p-val) & All significant & Except Job & All as expected \\
\cline { 2 - 5 } & Coefficient of variation & $1.10 \%$ & $6.50 \%$ & $2.70 \%$ \\
\cline { 2 - 4 } & Sign of the coefficient & All as expected & All as expected & All as expected \\
\hline
\end{tabular}

Table 8: Summary of the sensitivity of measures.

\section{Robustness check}

To check for robustness the study used different techniques of estimation (OLS and Tobit) as well as several measures for education, channels and fertility. For education and fertility as discussed, the results were found consistent and more robust with other pieces of research while using ideal number of children, age at first marriage on the fertility side and years of school and highest grade achieved on the education side. The change of measures of channels gives sometimes different results. For example, while introducing radio in the definition of the variable exposure to media, the results were puzzling as exposure to media was positively correlated with fertility. The reason could be that television and newspaper as components of exposure to media are more influential on behavior than radio. The variable women empowerment also was measured by different variables. While using only decision in family planning or woman can refuse to have sex the results were the same but less consistent. While combining the two measures, the results became more consistent. While removing some outliers ${ }^{6}$ with respects to the variables of interest (education, channels and fertility), the results became slightly different, but the main findings were the same. The non-linearity of the model was also checked as discussed for example by Bongaarts [48]; Bankole [49]. To that end, quadratic version of years to school was added in the models and the results were basically the same. Moreover, the use of grade of education which is not a continuous variable also helped to sort out this issue. The desire of children of the husband has also been controlled for. The magnitude of the results were slightly different but the findings remained unchanged. Globally the robustness check comforted the main findings that remained consistently unchanged despite some fluctuations in magnitudes.

\section{Caveats}

It is worthwhile to acknowledge two main limits and constraints regarding this study. The first one is related to Data. The data from IDHS are known to be of good quality. However, there were some limiting aspects for this study. The design of the surveys defines a woman at childbearing age a woman with aged from 15 to 49 , inducing then a selection bias for the women whose fertility could have appeared out of that conventional range of age. And this fact is more and more common in SSA due to early marriage and adolescent

\footnotetext{
6 For example, East Africa countries (Zimbabwe, Kenya) and Nigeria exhibits a much higher level of education compare to the others countries whereas Mali, Guinea, Malawi have a lower level.
} in SSA in 2010 [50]. Another potential bias is due to the risks of nonindependence between sampled women. Indeed, the sampling method used by DHS consisted in including all women of childbearing age within a selected household. Hence, in case of multiple women at childbearing age in the same household, many characteristics common to the household could have account for non-independence between individuals. However, the large size of the sample could have minimized the effects of these selection biases. The second problem is related to endogeneity which was omnipresent in this study. Indeed, the study made the assumption of non-recursive effect between education, channels and fertility. For example, Cynthia and Barbara [51] brought forth evidence on the fact that family formation and childbirth are factors that explain 5 to $10 \%$ of school dropout for young girls in SSA. Moreover, measuring education and fertility by indicators expressing the final fertility (number of children even born) or the final level of education (e.g., total years of schooling) could be misleading [52]. In a more realistic view, it should be consistent to consider that education and fertility can affect one another during the life course. Indeed, the fertility and the education attainment of a woman can evolve alternately so that her actual fertility might not be the result of her actual level of education but that of an anterior level and iteratively. To address this issue, some authors used the Structural Modeling Equations (SEM), but some others challenges are still remaining as these approaches used strong assumptions like the absence of measurement errors. (see for example Graff [53]; Ullman [54] for SEM). These limits suggest for further studies, a global setting to study the transmission mechanism using panel or cohort data or at least pseudo-panel with more consistent estimations techniques such as Instrumental Variable and/or Structural Equation Modelling.

\section{Conclusion}

\section{Main findings}

The well-known influence of education on decreasing fertility has been the starting point of this study which attempted to contribute to the research by discussing the channels through which education could consistently bring about a decline in fertility in Sub-Saharan Africa. Indeed, despite a high improvement in education in SSA, that region is just experiencing a slight decline in fertility with a high TFR compared pregnancy estimated at 1.8 million of girls giving birth before 15 years 
Page 14 of 15

to other regions in the world. Two core questions have then oriented the discussion: what are the main factors through which education influences fertility and what are the sensitivity with respect to measures usually used to capture fertility and education. A framework including four channels has been used to discuss these questions. Due to some serious issues of endogeneity, Logit, OLS and Tobits regressions have been used to capture the correlation between education and channels in a first step, and the association between channels and fertility in a second step. The sensitivity of the results was discussed using several measures of education and fertility. The results showed that regulation as measured by contraceptive use and exposure to media, was strongly associated with both education and fertility. The channels women empowerment and opportunity cost of having many children was globally found relatively weakly associated with education and fertility. However, it is worthwhile to notice that the measure used to capture women empowerment was much closer to a bargaining power than a real empowerment which by itself is quite tricky as concept. The current working status of the woman was also a weak proxy for the opportunity cost of having many children. These results have been found globally consistent with previous studies in terms of the expected signs as well as the magnitude of influence. This was the case, typically while using on the one hand total years of schooling and highest grade achieved to account for education and on the other hand ideal number of children and age at first marriage to account for fertility. The main other measures: literacy for education and number of children even born for fertility yield to less robust results.

\section{Policy implications}

These results are therefore compelling in terms of possible policies in order to gain from the substantial investment in education in SSA, such as to enhance the decline in fertility in that part of the world. Thus, the high association of regulation and exposure to media with both education and fertility suggest that the authorities of SSA countries should:

- Enhance educational programs and tackle particularly issues inducing early dropout so as to gain on the supply side in terms of postponement of marriage for girls due to the time constraint related to school. They should also promote secondary and tertiary school, manage to reduce the gender gap and address the issue of the learning outcomes through an improvement of infrastructures and educational system including the training and the monitoring of teachers.

- Moreover, the educational curriculum in SSA should include fertility and sexuality related topics in order to educate young girls on fertility's issues. This will basically affect the demand side of fertility. A typical illustration of such policy is what was known as West African Youth Initiative (WAYI) peer education projects implemented from 1994-1997 to improve knowledge of sexuality and reproductive health and promote safer sex behaviors and contraceptive use among sexually active adolescents in Nigeria and Ghana. The post evaluation of these projects showed evidence of an improvement of knowledge and a change in behaviour regarding sexual matters [55].

- SSA authorities should also promote exposure to media with particular programs that aim at advertising family planning, access and knowledge on contraceptive use as advocated by William [56] and John [57].

\section{References}

1. UN (2013) Fertility-United Nations Population Division.

2. Bongaarts $J$ (2013) How exceptional is the pattern of the fertility decline in sub-Saharan Africa. UN Population Division.

3. Jean D, Mamta M (2000) Fertility, education and development: Further evidence from India. LSE Research Online.

4. Gerhard M (2008) How universal is the negative correlation between education and fertility? J Soc Polit Econ Stud 33: 205.

5. Guang-zhen W, Buffalo MD (2004) Social and cultural determinants of attitudes toward abortion: A test of Reiss hypotheses. Soc Sci J 41: 93-105.

6. IIASA (2014) Rethinking Population Policies Why Education Makes a Decisive Difference-Policy Briefs-International Institute for Applied Systems Analysis.

7. Ezeh AC, Blessing UM, Jacques OE (2009) Stall in fertility decline in Eastern African countries: regional analysis of patterns, determinants and implications. Biological Sciences 364: 2991-3007.

8. Alex CE, Blessing UM and Jacques OE (2009) Stall in fertility decline in Eastern African countries: regional analysis of patterns, determinants and implications. Philosophical Transactions of the Royal Society of London B: Biological Sciences, 364: 2991-3007.

9. UN (2015) The Millennium Development Goals Report 2015. New York.

10. Kevin W (2013) Too Little Access, Not Enough Learning: Africas Twin Deficit in Education.

11. Cochrane SH (1979) Education and fertility: What do we really know. Johns Hopkins, Baltimore.

12. Becker GS (1960) An economic analysis of fertility. Columbia University Press, London.

13. Easterlin RA (1975) An economic framework for fertility analysis. Studies in family planning 6: 54-63.

14. Butalo RA, Ronald DL, Paula EH, Bongaarts JP (1983) Determinants of fertility in developing countries. Int Fam Plan Perspect 8: 116-121.

15. Bongaarts J (1978) A framework for analyzing the proximate determinants of fertility. Popul Dev Rev 4: 105-132.

16. Lisa M, Michael G, Hillard K, Jonathan S (2012) Why do women have more children than they want? Understanding differences in women's ideal and actual family size in a natural fertility population. Am J Hum Biol 24: 786-799.

17. Yoram BP (1976) Fertility response to child mortality: micro data from Israel. J Polit Econ 84: S163-S178.

18. Basu D, Robert DJ (2010) Son targeting fertility behavior: Some consequences and determinants. Demography 47: 521-536.

19. Latifat DGI (2010) Fertility transition in Nigeria: Exploring the role of desired number of children.

20. Muhoza DN, Annelet B, Pieter H (2014) Variations in desired family size and excess fertility in East Africa. Int J Popul Res.

21. David, Clara D (2015) Religions, Fertility and Growth in South- East Asia. Technical report.

22. Charles FW (2010) Desired number of children: 2000-2008. DHS Comparative Reports.

23. Larry RP (2001) Religion, plausibility structures, and education's effect on attitudes toward elective abortion. J Sci Study Relig 40: 187-204.

24. Anna N (2010) Implications of sex and education on abortion attitudes: a cross-sectional analysis.

25. Tadesse B, Sisay A (2001) Are More Children a Blessing? Determinants of the Demand for Children in Jimma, Ethiopia. Int Conference African Dev Arch.

26. Ribar DC (1992) Child care and the labor supply of married women: Reduced form evidence. J Hum Resour 27: 134-165.

27. Testa MR (2014) On the positive correlation between education and fertility intentions in Europe: Individual-and country-level evidence. Adv Life Course Res 21: 28-42.

28. Baudin T (2015) Religion and fertility: The French connection. Demogr Res 32: 397. 
Citation: Ndjanmou TB (2017) Women's Education and Fertility in Sub-Saharan Africa: Channels and Influence of Education on Fertility. J Glob

29. Upadhyaya UD, Deborah K (2012) Women's empowerment and ideal family size: An examination of DHS empowerment measures in subSaharan Africa. Int Perspect Sex Reprod Health 38: 78-89.

30. Upadhyaya UD (2014) Women's empowerment and fertility: A review of the literature. Soc Sci Med 115: 111-120.

31. Suguna M (2011) Education and women empowerment in India. Zenith International Journal of Multidisciplinary Research 1: 196-204.

32. Mberu BU, Reed HE (2014) Understanding Subgroup Fertility Differentials in Nigeria. Popul Rev 53: 23-46.

33. Bongaarts J, John C (2013) Fertility Transition: Is Sub-Saharan Africa Different? Popul Dev Rev 38: 153-168.

34. Caldwell J (1999) Paths to lower fertility. Br Med J 319: 985-987.

35. Charles FW, Akinrinola B (2001) The contraception-fertility link in subSaharan Africa and in other developing countries.

36. Ndahindwa V (2014) Determinants of fertility in Rwanda in the context of a fertility transition: a secondary analysis of the 2010 Demographic and Health Survey. Reprod Health 11: 87.

37. Douglas BK (2008) The impact of abstinence and comprehensive sex and STD/HIV education programs on adolescent sexual behavior. Sex Res Social Policy 5: 18-27.

38. Cheng KW (2011) The effect of contraceptive knowledge on fertility: The roles of mass media and social networks. J Fam Econ Issues 32: 257-267.

39. McCrary J, Heather R (2006) The effect of female education on fertility and infant health: Evidence from school entry policies using exact date of birth. NBER Work Pap Ser.

40. Muvawala J (2012) Determinants of learning outcomes for primary education: A case of Uganda. S Afr Stat J 15: 42-54.

41. Kurnaz M (2015) Job Market Paper.

42. Ainsworth M (1989) Socioeconomic determinants of fertility in Cote dIvoire.

43. Osili UO, Bridget TL (2008) Does female schooling reduce fertility? Evidence from Nigeria. J Dev Econ 87: 57-75.
44. Abadian S (1996) Women's autonomy and its impact on fertility. World Dev 24: 1793-1809.

45. Bloom DE (2009) Fertility, female labor force participation, and the demographic dividend. J Econ Growth 14: 79-101.

46. Westoff CF (1992) Age at marriage, age at first birth, and fertility in Africa. The World Bank.

47. Westoff CF, Akinrinola B (1997) Mass media and reproductive behavior in Africa.

48. Kodzi IA, John BC, Peter A (2010) The time dynamics of individual fertility preferences among rural Ghanaian women. Stud Fam Plann 41: $45-54$.

49. Bongaarts $J$ (2010) The causes of educational differences in fertility in sub-Saharan Africa.

50. Bankole A (1995) Desired fertility and fertility behaviour among the Yoruba of Nigeria: A study of couple preferences and subsequent fertility. Popul Stud 49: 317-328.

51. UNFP (2013) Adolescent Pregnanc. UNFPA-United Nations Population Fund.

52. Cynthia BL, Barbara SM (2008) Marriage and childbirth as factors in dropping out from school: an analysis of DHS data from sub-Saharan Africa. Popul Stud 62: 1-13.

53. Ronald RR, Larry B, Craig J (1980) Education and fertility: Implications for the roles women occupy. Am Sociol Rev 45: 431-447.

54. Graff M (2010) Childhood nutrition and later fertility: Pathways through education and pre- pregnant nutritional status. Demography 47: 125-144.

55. Ullman JB (2006) Structural equation modeling: Reviewing the basics and moving forward. J Pers Assess 87: 35-50.

56. William RB (2001) West African youth initiative: outcome of a reproductive health education program. J Adolesc Health 29:436-446.

57. John B (2011) Can family planning programs reduce high desired family size in sub- Saharan Africa? Int Perspect Sex Reprod Health 37: 209-216. 